\title{
Dynamics of $\operatorname{Br}\left({ }^{2} \mathbf{P}_{j}\right)$ Formation in the Photodissociation of Bromobenzene
}

\author{
Dababrata Paul, Hyun Kook Kim, Kiryong Hong, and Tae Kyu Kim* \\ Department of Chemistry and Chemistry Institute of Functional Materials, Pusan National University, Busan 609-735, Korea \\ *E-mail: tkkim@pusan.ac.kr \\ Received December 15, 2010, Accepted January 14, 2011
}

\begin{abstract}
The photodissociation dynamics of bromobenzene near $234 \mathrm{~nm}$ has been investigated using a two-dimensional photofragment ion-imaging technique coupled with a state-selective [2+1] resonance-enhanced multiphoton ionization (REMPI) scheme. The nascent $\mathrm{Br}$ atoms are produced by the primary $\mathrm{C}-\mathrm{Br}$ bond dissociation, which leads to the formation of $\mathrm{C}_{6} \mathrm{H}_{5}(\tilde{X})$ and $\mathrm{Br}\left({ }^{2} \mathrm{P}_{j}, j=1 / 2,3 / 2\right)$. The observed translational energy distributions have been fitted by a single Boltzmann function and two Gaussian functions. Trimodal translational energy distributions of $\operatorname{Br}\left({ }^{2} \mathrm{P}_{j}\right)$ have been assigned to the direct/indirect dissociation mechanisms originating from the initially excited ${ }^{3}\left(\pi, \pi^{*}\right)$ state. The assignments have been confirmed by the recoil anisotropy and distribution width corresponding to the individual components.
\end{abstract}

Key Words: Photodissociation dynamics, Aryl halides, Ion-imaging

\section{Introduction}

Recently, numerous experimental and theoretical studies have been carried out to unravel the photodissociation dynamics of organic halides that have $\mathrm{C}-\mathrm{X}(\mathrm{X}=\mathrm{Cl}, \mathrm{Br}$, and $\mathrm{I})$ bonds in the ultraviolet (UV) region. ${ }^{1-5}$ Most of these studies have focused on the mechanism of formation of $\mathrm{X}$ atoms in the ground $\left({ }^{2} P_{3 / 2}\right)$ and excited $\left({ }^{2} P_{1 / 2}\right)$ spin-orbit states. In the case of alkyl halides, which are the simplest organic halides, diffuse absorption continua at short UV wavelengths are characteristic of repulsive excited states. They originate from $\sigma^{*} \leftarrow n$ electronic transitions that are localized on $\mathrm{C}-\mathrm{X}$ bonds and result a prompt dissociation. The detailed dynamics related to state-selective photodissociation and nonadiabatic interaction among potential energy surfaces have been elucidated on the basis of energy distributions, recoil anisotropy parameters, and relative quantum yields of nascent $\mathrm{X}$ atoms. ${ }^{6-10}$

When an organic halide contains another chromophore such as $\mathrm{C}=\mathrm{C}$ and $\mathrm{C}=\mathrm{O}$ moieties, the dynamics become more complicated. For example, in the case of aryl halides $\left(\mathrm{C}_{6} \mathrm{H}_{5} \mathrm{X}\right)$, the dynamics of dissociation become more complicated because of another chromophore on the benzene ring. ${ }^{6,11-19}$ By far-UV excitation, aryl halides are excited to the lowest singlet state $\left(\pi, \pi^{*}\right)$, which is delocalized on the benzene ring, and X atoms are produced via predissociation to the triplet $\left(n, \sigma^{*}\right)$ localized on the $\mathrm{C}$-X bond. ${ }^{16,20}$ The dynamics of the predissociation depend on the coupling strength between these electronic states, which is influenced by the type of halogen, ${ }^{13}$ the substituents on the benzene ring, ${ }^{21-24}$ and the excitation wavelength.

In particular, the photodissociation dynamics of bromobenzene has been investigated using photofragment translational spectroscopy, photofragment ion-imaging, and femtosecond spectroscopy. ${ }^{11,12,16}$ Recently, the effects of the halogen substituents on the dissociation of bromobenzene have also been studied. ${ }^{14,25-27}$ However, all the studies have concentrated on the dynamics near $270 \mathrm{~nm}$; at these dynamics the $\pi^{*} \leftarrow \pi$ transition dominates the absorption spectrum. In short wavelength region, considerable UV absorption is caused by $\sigma^{*} \leftarrow n$ transition and the $\pi^{*} \leftarrow \pi$ transition. This may imply that the two transitions interact with each other. Therefore, revealing the photodissociation dynamics in this wavelength region seems to be a more interesting topic. However, only a relative quantum yield near $234 \mathrm{~nm}$ has been measured, ${ }^{12}$ and more information is necessary to explain and to gain a detailed understanding of the complex photodissociation dynamics of bromobenzene in this wavelength region.

In the present study, we investigate the photodissociation dynamics of bromobenzene $\left(\mathrm{C}_{6} \mathrm{H}_{5} \mathrm{Br}\right)$ near $234 \mathrm{~nm}$, which is the wavelength at which the dissociation dynamics is expected to be more complicated than that at $266 \mathrm{~nm} .^{11,13}$ The two-dimensional photofragment ion-imaging technique was used to obtain the spatial distributions of the nascent $\mathrm{Br}$ atoms. The $[2+1]$ resonance-enhanced multiphoton ionization (REMPI) scheme was used for state-selective detection of $\operatorname{Br}\left({ }^{2} P_{3 / 2}\right)$ and $\operatorname{Br} *\left({ }^{2} P_{1 / 2}\right)$ that were generated after photolysis of $\mathrm{C}_{6} \mathrm{H}_{5} \mathrm{Br}$. The extracted distributions of the total translational energy, the extracted recoil anisotropic parameters, and the determined relative quantum yields were used to elucidate the complicated photodissociation dynamics of $\mathrm{C}_{6} \mathrm{H}_{5} \mathrm{Br}$ in detail. The potential energy curves calculated in recent theoretical studies were considered and compared with our experimental findings. ${ }^{13,14}$

\section{Experiment}

The experimental setup used in this study has been described elsewhere in detail. ${ }^{27,28}$ Briefly, our velocity mapping apparatus $^{29}$ consists of a supersonic molecular-beam source, a timeof-flight (TOF) mass spectrometer, and a position-sensitive detector. A sample mixture was prepared with $1.5 \%$ of $\mathrm{C}_{6} \mathrm{H}_{5} \mathrm{Br}$ (Aldrich, 97\%) seeded in He at a stagnation pressure of approximately $1.4 \mathrm{~atm}$. The molecular beam was introduced using a pulsed valve (General Valve, Series 9) with an $800 \mu \mathrm{m}$ orifice diameter that was operated synchronously with the laser pulse, which was typically $10 \mathrm{~Hz}$. The molecular beam entered into the 
ionization region of the main chamber through both a skimmer and a pinhole with a diameter of $1 \mathrm{~mm}$, and it intersected the laser pulse perpendicularly.

The $355 \mathrm{~nm}$ output of a pulsed Nd:YAG laser (Spectra Physics, GCR-170) was used to pump a dye laser (Lumonics, HD500). An automated phase-matching system (Lumonics, HT1000) was used for frequency doubling to generate linearly polarized UV laser light. This light was focused into an ionization region by a plano-convex lens with a focal length of 150 mm. It photolyzed $\mathrm{C}_{6} \mathrm{H}_{5} \mathrm{Br}$ to produce $\mathrm{Br}$ and $\mathrm{Br}^{*}$, which were ionized selectively in the single pulse using [2+1] REMPI schemes at 233.69 and $234.03 \mathrm{~nm}$ via $6 p{ }^{4} P_{3 / 2}$ and $6 p{ }^{4} D_{1 / 2}$ intermediate states, respectively. ${ }^{30}$ The resulting $\mathrm{Br}$ ion clouds were accelerated and focused by an electrostatic lens ${ }^{29}$ onto a position-sensitive detector, which was composed of a dual-chevron microchannel plate, a phosphor screen (Galileo, FM3040), and a charge-coupled-device (CCD) camera (Photometrics, $\mathrm{CH} 250$ ). A nonhomogeneous electrical field was induced around the electrode to accelerate and map the spherically expanded bromine ion clouds toward a position-sensitive detector. A negative high voltage with a $150 \mathrm{~ns}$ duration was applied to the image intensifier to segregate the $\mathrm{Br}$ ion signals from background noises stemming from scattered light and ions from different masses.

10000 laser shots were averaged to construct the image. The background was removed by subtracting the reference image, which was collected at an off-resonance wavelength from the relevant images under the same conditions. To acquire the REMPI TOF spectra, a photomultiplier tube (Hamamatsu, 1P21) was used instead of the CCD camera. All images and spectra were averaged over a range of $\pm 0.4 \mathrm{~cm}^{-1}$ to cover all velocity components of the $\mathrm{Br}$ atoms.

\section{Results and Analysis}

The raw images of $\mathrm{Br}$ and $\mathrm{Br}^{*}$ produced by the $234 \mathrm{~nm}$ photolysis of $\mathrm{C}_{6} \mathrm{H}_{5} \mathrm{Br}$ are presented in Figures 1(a) and 1(b), respectively. The polarization vector of the laser pulse was vertically aligned in each case. Since the two-dimensional raw image is a projection of three-dimensional speed and angular distribution with cylindrical symmetry around the axis of the photolysis laser, the shape of the raw image contains information about the vector distribution of the photofragments. The three-dimensional velocity distribution was deduced from the raw image using the inverse Abel transformation. Cylindrical
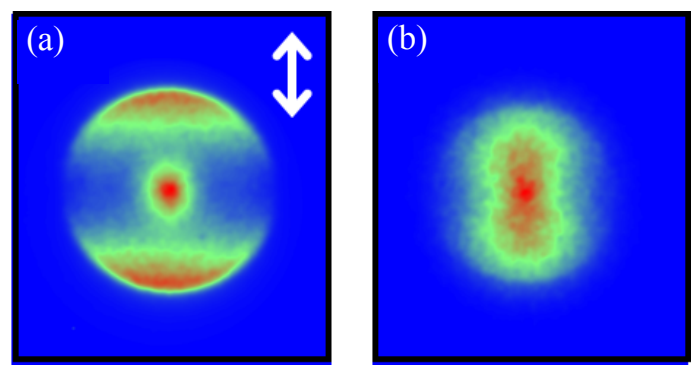

Figure 1. Raw images of $\mathrm{Br}(\mathrm{a})$ and $\mathrm{Br}^{*}$ (b) ions from the photolysis of $\mathrm{C}_{6} \mathrm{H}_{5} \mathrm{Br}$. In all of the images, the polarization of the photolysis laser is aligned vertically. symmetry around the photolysis laser axis allows one to reconstruct a three-dimensional image from every image slice containing the symmetry axis. ${ }^{31}$ Before the transformation, the image was presmoothed using a $5 \times 5$ Gaussian filter with a standard deviation of 2 , because the inverse Abel transformation is very sensitive to noise. ${ }^{31}$

The angular distribution $P(\theta)$ can be deduced by integrating the reconstructed three-dimensional speed distribution over a proper range of speed at each angle. The translational anisotropy parameter $\beta$ can be obtained by fitting $P(\theta)$ with the following formula:

$$
P(\theta) \propto 1+\beta P_{2}(\cos \theta)
$$

where $\theta$ is the angle between the recoil velocity vector of the photofragments and the polarization axis of the laser. $P_{2}(\cos \theta)$ is the second-order Legendre polynomial. ${ }^{32}$ The averaged values are $\beta(\mathrm{Br})=1.20 \pm 0.03$ and $\beta\left(\mathrm{Br}^{*}\right)=0.61 \pm 0.03$ for $\mathrm{C}_{6} \mathrm{H}_{5} \mathrm{Br}$. The values, which deviate from the limiting cases, can be traced to different origins, such as the long lifetime of the excited state, predissociation, and the deviation of the recoil axis from the transition dipole moment. It should also be mentioned that multiple channels contribute to the formation of $\mathrm{Br}$ and/or $\mathrm{Br}^{*}$ in the photolysis of $\mathrm{C}_{6} \mathrm{H}_{5} \mathrm{Br}$. These finding can be clearly seen by the total translational energy distribution, which is characterized by several components.

The speed distribution can be extracted by integrating the reconstructed three-dimensional speed distributions over all angles at each speed. The center-of-mass translational energy distribution, $P(E)$, was obtained by the speed distribution using the following equations:

$$
\begin{aligned}
& P\left(E_{T}\right) d E=P(v) d v \\
& E_{T}=\frac{1}{2}\left(m_{\mathrm{Br}}+m_{\mathrm{C}_{6} \mathrm{H}_{5}}\right) \times \frac{m_{\mathrm{Br}}}{m_{\mathrm{C}_{6} \mathrm{H}_{5}}} \times v_{\mathrm{Br}}^{2}
\end{aligned}
$$

The total translational energy distributions for $\mathrm{Br}$ and $\mathrm{Br}$ * from $\mathrm{C}_{6} \mathrm{H}_{5} \mathrm{Br}$ are displayed in Figure 2. Each translational energy distributions of $\mathrm{Br}$ and $\mathrm{Br}^{*}$ in $\mathrm{C}_{6} \mathrm{H}_{5} \mathrm{Br}$ can be well fitted by three distribution components (one Boltzmann and two Gaussian functions), implying that at least three formation channels are involved in the photodissociation of $\mathrm{C}_{6} \mathrm{H}_{5} \mathrm{Br}$. This feature will be discussed later. To deduce the contributions of each component to the recoil anisotropy parameter, $\beta$ values corresponding to individual translational energy values were extracted; these are also displayed in Figure 2. $\beta$ values from $\mathrm{C}_{6} \mathrm{H}_{5} \mathrm{Br}$ were found to vary from -0.01 to 1.62 in the case of $\mathrm{Br}$ and from 0.22 to 1.04 in the case of $\mathrm{Br}^{*}$.

The average translational energies for individual Gaussian distributions were determined. For $\mathrm{C}_{6} \mathrm{H}_{5} \mathrm{Br}$, each Gaussian component is denoted as $\left\langle E_{T}\right\rangle_{\text {middle }}$ and $\left\langle E_{T}\right\rangle_{\text {high }}$ based on the order of energy. All of these values are listed in Table 1. The available energy $\left(E_{a v l}\right)$ can be calculated by the following equation:

$$
E_{a v l}=E_{h v}-D_{0}-E_{e l}+E_{\text {int }}
$$


(a)

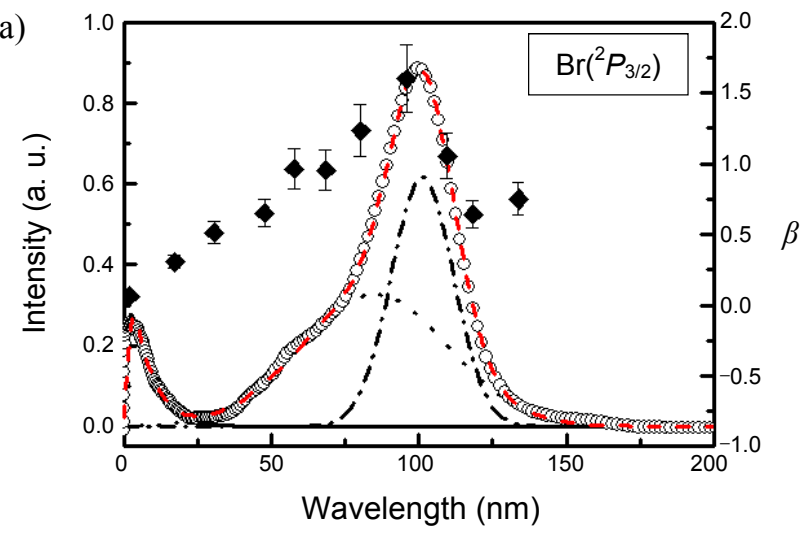

(b)

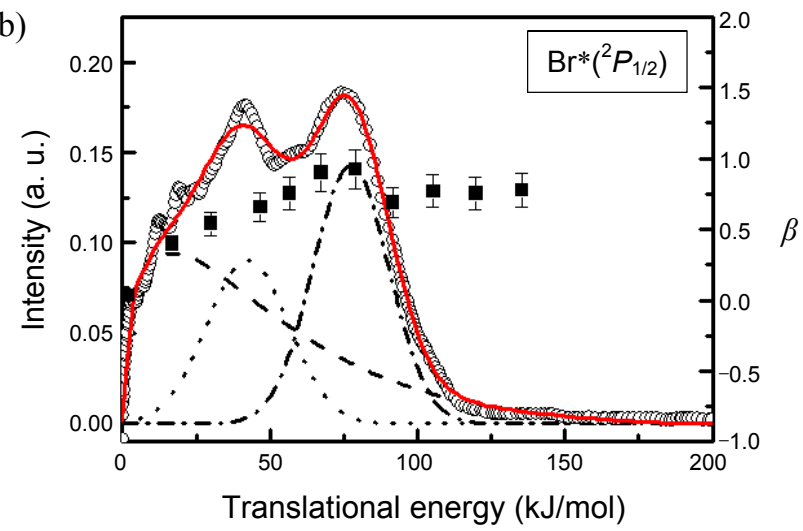

Figure 2. Total translational energy distributions of $\mathrm{Br}$ (a) and $\mathrm{Br}$ * (b) from photodissociation of $\mathrm{C}_{6} \mathrm{H}_{5} \mathrm{Br}$. $\beta$ values with error bars corresponding to individual translational energy values are also displayed. Each data point (shown as open circles) corresponds to the relative signal intensity obtained by integrating values for all angular components at a specific translational energy. The anisotropy parameters (shown as filled diamonds in the axes on the right) are also displayed as a function of the translational energy. In all of the figures, the dashed lines (---) denote static distributions. The dotted lines ( $(\cdots)$ and dashdotted lines (---) correspond to the low and high Gaussian components, respectively. The linear combinations of overall components are displayed as solid lines.

Table 1. The average translational energy and $f_{T}$ values for each translational energy component of $\mathrm{C}_{6} \mathrm{H}_{5}+\mathrm{Br}\left(\mathrm{Br}^{*}\right)$ channels at 234 $\mathrm{nm}$. All energy values are in $\mathrm{kJ} / \mathrm{mol}$.

\begin{tabular}{ccccccc}
\hline Channel & $E_{\text {avl }}$ & $E_{T \text {,low }}^{\text {peak }}$ & $\left\langle E_{T}\right\rangle_{\text {middle }}$ & $\left\langle E_{T}\right\rangle_{\text {high }}$ & $f_{T}^{\text {middle }}$ & $f_{T}^{\text {high }}$ \\
\hline $\mathrm{C}_{6} \mathrm{H}_{5}+\mathrm{Br}$ & 168.6 & 3.05 & 85.3 & 101.0 & 0.45 & 0.60 \\
$\mathrm{C}_{6} \mathrm{H}_{5}+\mathrm{Br} *$ & 124.6 & 14.2 & 42.3 & 76.7 & 0.34 & 0.62 \\
\hline
\end{tabular}

where $E_{h v}, D_{0}, E_{e l}$, and $E_{\text {int }}$ denote the photon energy, the bond dissociation energy of $\mathrm{C}-\mathrm{Br}$, the electronic energy of $\mathrm{Br}$ atoms, and the internal energy of a parent molecule, respectively. $D_{0}=342.8 \mathrm{~kJ} / \mathrm{mol}$ was chosen for $\mathrm{C}_{6} \mathrm{H}_{5} \mathrm{Br}$. ${ }^{11} E_{e l}$ values were assumed to be $0 \mathrm{~kJ} / \mathrm{mol}$ for $\mathrm{Br}$ and $44 \mathrm{~kJ} / \mathrm{mol}$ for the excited state $\mathrm{Br}^{*}$. Since the rotational and vibrational excitations are negligible in a supersonic molecular beam, $E_{\text {int }}$ was estimated to be zero. The fraction of the average translational energy for each component over the available energy, $f_{T}$, is also listed in Table 1.
Table 2. The branching ratios, relative quantum yields, and representing $\beta$ values for each translational energy component of the $\mathrm{C}_{6} \mathrm{H}_{5}+$ $\mathrm{Br}(\mathrm{Br} *)$ channels at $234 \mathrm{~nm}$

\begin{tabular}{ccccc}
\hline Channel & $\Phi_{\text {low }}^{\mathrm{BZ}}$ & $\Phi_{\text {middle }}^{\mathrm{GS}}$ & $\Phi_{\text {high }}^{\mathrm{GS}}$ & $\Phi_{\text {TOTAL }}$ \\
\hline $\mathrm{C}_{6} \mathrm{H}_{5}+\mathrm{Br}$ & 0.06 & 0.47 & 0.38 & 0.91 \\
$\mathrm{C}_{6} \mathrm{H}_{5}+\mathrm{Br} *$ & 0.04 & 0.02 & 0.03 & 0.09 \\
$\mathrm{Br} * \mathrm{Br}$ & 0.66 & 0.04 & 0.08 & - \\
$\beta$ value for $\mathrm{Br}$ & -0.01 & 0.98 & 1.62 & - \\
$\beta$ value for $\mathrm{Br}^{*}$ & 0.02 & 0.69 & 1.04 & - \\
\hline
\end{tabular}

The relative quantum yields for $\mathrm{Br}$ and $\mathrm{Br}$ * have been determined from the relative peak intensity of the TOF spectra. The measured ion-signal ratio is proportional to the product ratio by the factor of $k$,

$$
\frac{N\left(\mathrm{Br}^{*}\right)}{N(\mathrm{Br})}=k \frac{S(\mathrm{Br} *)}{S(\mathrm{Br})}
$$

where $N(\mathrm{X})$ and $S(\mathrm{X})\left(\mathrm{X}=\mathrm{Br}\right.$ and $\left.\mathrm{Br}^{*}\right)$ designate the number and the measured signal intensity of the species $\mathrm{X}$, respectively. The proportional factor $k$ is related to the experimental setup and the relative REMPI efficiency of $\mathrm{Br}$ and $\mathrm{Br}^{*}$. A value of $k=0.24$ was obtained for the experimental conditions used in this study.

$$
\Phi\left(\mathrm{Br}^{*}\right)=\frac{N\left(\mathrm{Br}^{*}\right)}{N\left(\mathrm{Br}^{*}\right)+N(\mathrm{Br})}
$$

The resulting quantum yield was $\Phi\left(\mathrm{Br}^{*}\right)=0.09 \pm 0.01$ for $\mathrm{C}_{6} \mathrm{H}_{5} \mathrm{Br}$. Following these values, the relative quantum yields for each energy component in Figure 2 were extracted and are listed in Table 2.

\section{Discussion}

In the $234 \mathrm{~nm}$ photodissociation of $\mathrm{C}_{6} \mathrm{H}_{5} \mathrm{Br}$, the total translational energy distributions of $\mathrm{Br}$ and $\mathrm{Br} *$ were well-fitted by a single Boltzmann function and two Gaussian distributions (see Figure 2). Since each component stems from one or more processes, at least three dissociation pathways must be considered to identify the origins of individual components in the $\mathrm{C}$ - $\mathrm{Br}$ bond fission of $\mathrm{C}_{6} \mathrm{H}_{5} \mathrm{Br}$ at $234 \mathrm{~nm}$. In the present study, energetically accessible electronic states leading to the formation of $\mathrm{C}_{6} \mathrm{H}_{5}(\tilde{X})$ and $\mathrm{Br}\left(\mathrm{Br}^{*}\right)$ can be inferred from recent theoretical studies. According to the recent multireference CASSCF and CASPT2 calculations by Liu et al., ${ }^{13,14} A_{1}{ }^{3}\left(\pi, \pi^{*}\right), B_{2}{ }^{1}\left(\pi, \pi^{*}\right)$, and $B_{1}{ }^{3}\left(n, \sigma^{*}\right)$ states (in ascending order of energy) can be reached at $234 \mathrm{~nm}(\sim 5.3 \mathrm{eV})$. The $B_{1}{ }^{1}\left(\pi, \sigma^{*}\right)$ state lies much higher than the photo energy, and its contribution to the photodissociation can be ignored. $A_{1}{ }^{3}\left(\pi, \pi^{*}\right)$ has a barrier into the exit channel, and the energy of the exit barrier is higher than that of the excitation energy. Therefore, $B_{2}{ }^{1}\left(\pi, \pi^{*}\right)$ and $B_{1}{ }^{3}\left(n, \sigma^{*}\right)$ states are responsible for the formation of $\mathrm{Br}$ atoms in the photodissociation of $\mathrm{C}_{6} \mathrm{H}_{5} \mathrm{Br}$ at $234 \mathrm{~nm}$. A schematic diagram representing potential energy surfaces for $\mathrm{C}_{6} \mathrm{H}_{5} \mathrm{Br}$ taken 


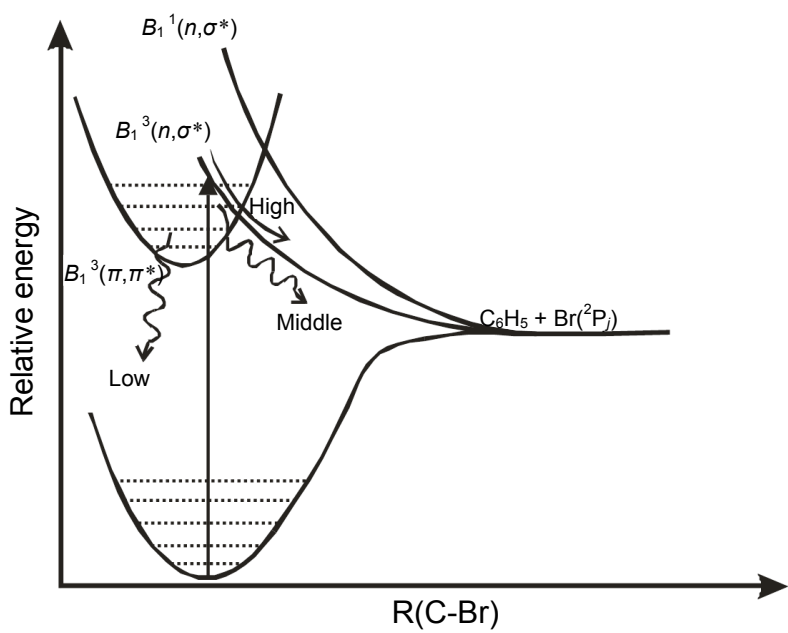

Figure 3. Schematic diagram representing the photodissociation of $\mathrm{C}_{6} \mathrm{H}_{5} \mathrm{Br}$ at $234 \mathrm{~nm}$. The energy and order of each state are adopted from Refs. 13 and 14.

from CASSCF and CASPT2 calculations is shown in Figure 3.

As shown in Figures 2(a) and 2(b), Boltzmann components have been observed in $\mathrm{C}_{6} \mathrm{H}_{5} \mathrm{Br}$, and translational energy distributions for the components of $\mathrm{Br}$ and $\mathrm{Br} *$ are well characterized by Boltzmann-shaped functions peaking at 3.0 and 17.0 $\mathrm{kJ} / \mathrm{mol}$, respectively. Isotropic angular distributions were found for both $\operatorname{Br}(\beta=0.02)$ and $\mathrm{Br}^{*}(\beta=0.35)$ formation channels. Both Boltzmann translational energy distribution and isotropic angular distribution suggest that indirect dissociation following the electronic relaxation process is responsible for the formation of low-velocity components. ${ }^{33}$ Similar shaped energy profiles and multimodal translational energy distributions of $\mathrm{Cl}$ $\left(\mathrm{Cl}^{*}\right)$ have been found in $\mathrm{C}_{6} \mathrm{H}_{5} \mathrm{Cl}$ and $\mathrm{C}_{6} \mathrm{~F}_{5} \mathrm{Cl}$ photodissociations at $248 \mathrm{~nm} .{ }^{17}$ These findings have been interpreted as an indication that the origin of the statistical component depends on internal conversion from the initially excited ${ }^{1}\left(\pi, \pi^{*}\right)$ state into the vibrationally excited ground state. Therefore, it seems reasonable to conclude that the Boltzmann component in $\mathrm{C}_{6} \mathrm{H}_{5} \mathrm{Br}$ results from internal conversion followed by singlet-state excitation. It is generally believed that this excited singlet ${ }^{1}\left(\pi, \pi^{*}\right)$ state is a turning point to various dissociation pathways for the monohalobenzene UV photoreactions. ${ }^{13,16,20}$ The relative fraction for this fast internal conversion process was found to be 0.1 in the case of $\mathrm{C}_{6} \mathrm{H}_{5} \mathrm{Br}$, indicating that almost all initially excited molecules go through another dissociation pathway rather than the suggested fast internal conversion. In the $\mathrm{C}_{6} \mathrm{H}_{5} \mathrm{Cl}$ photodissociation, fractions of 0.39 at $193 \mathrm{~nm}$ and 0.64 at 248 $\mathrm{nm}$ have been measured. This difference might be due to the four-times-larger spin-orbit coupling energy of $\mathrm{Br}(44 \mathrm{~kJ})$ than that of $\mathrm{Cl}(10.5 \mathrm{~kJ})$. The probability of fast internal conversion from the initially excited ${ }^{1}\left(\pi, \pi^{*}\right)$ state in $\mathrm{C}_{6} \mathrm{H}_{5} \mathrm{Br}$ is much lower than that in the photodissociation of $\mathrm{C}_{6} \mathrm{H}_{5} \mathrm{Cl}^{17}$

Gaussian-shaped translational energy distributions for middle-velocity components of $\mathrm{Br}$ and $\mathrm{Br} *$ from $\mathrm{C}_{6} \mathrm{H}_{5} \mathrm{Br}$ have been observed. The broad energy distributions and low anisotropic parameters $\left(\beta=0.98\right.$ for $\mathrm{Br}$ and $\beta=0.69$ for $\left.\mathrm{Br}^{*}\right)$ imply the involvement of the predissociation mechanism in the formation of these components. The fractions of the average translational energies of $\mathrm{Br}$ and $\mathrm{Br}^{*}$ were measured to be 0.40 and 0.34 , respectively. The curve crossing from the initially pumped $B_{2}{ }^{1}\left(\pi, \pi^{*}\right)$ state to the repulsive $B_{1}{ }^{3}\left(n, \sigma^{*}\right)$ state may be the origin of these middle components. In experimental studies of the photodissociation of $\mathrm{C}_{6} \mathrm{H}_{5} \mathrm{Br}$ at $266 \mathrm{~nm},{ }^{11}$ it was suggested that this predissociation process is the only $\mathrm{Br}$ atom formation channel. The time constant of this predissociation has been measured to be 28 ps. ${ }^{16}$ As stated previously, the spin-orbit coupling between ${ }^{1}\left(\pi, \pi^{*}\right)$ and ${ }^{3}\left(n, \sigma^{*}\right)$ in the case of $\mathrm{C}_{6} \mathrm{H}_{5} \mathrm{Br}$ is much greater than that in $\mathrm{C}_{6} \mathrm{H}_{5} \mathrm{Cl}$. In the case of $\mathrm{C}_{6} \mathrm{H}_{5} \mathrm{Cl}$, the time constant of the predissociation channel has been found to be $1 \mathrm{~ns},{ }^{16}$ which is slower than that in $\mathrm{C}_{6} \mathrm{H}_{5} \mathrm{Br}$. The trend of this fast predissociation channel in the photodissociation of monohalobenzene has been predicted in recent theoretical studies. ${ }^{13}$

Direct dissociation from the repulsive $B_{1}{ }^{3}\left(n, \sigma^{*}\right)$ state forms the high-velocity components. Thus narrow Gaussian energy distributions and high anisotropy parameters are expected. These agree well with experimental findings, as shown in Figure 2. Moreover, the $\beta$ value (1.62) of this component for the $\mathrm{Br}^{*}$ channel is close to the limit value of the parallel transition $(\beta=2.00)$. This suggests that the high velocity components originate solely from direct dissociation via the repulsive $B_{1}{ }^{3}\left(n, \sigma^{*}\right)$ state. Similar phenomena have been found in the case of $\mathrm{C}_{6} \mathrm{H}_{5} \mathrm{I}$ at $266 \mathrm{~nm}$. El-Sayed et al. as well as Zewail et al. have proposed that fast dissociation is due to a direct dissociation of the repulsive ${ }^{3}\left(n, \sigma^{*}\right)$ state and slow dissociation mainly originates from curve crossing from the ${ }^{3}\left(\pi, \pi^{*}\right)$ state to the repulsive ${ }^{1}\left(n, \sigma^{*}\right)$ state. ${ }^{18,20,21}$ The lack of direct dissociation by the repulsive ${ }^{3}\left(n, \sigma^{*}\right)$ state in the photodissociation of $\mathrm{C}_{6} \mathrm{H}_{5} \mathrm{Br}$ at $266 \mathrm{~nm}^{11,16}$ can be attributed to the high excitation energy of the ${ }^{3}\left(n, \sigma^{*}\right)$ state. The vertical excitation energy of the ${ }^{3}\left(n, \sigma^{*}\right)$ state is about $5.26 \mathrm{eV}$, which is $0.6 \mathrm{eV}$ higher than the $266 \mathrm{~nm}$ $(4.66 \mathrm{eV})$ excitation energy used in the previous experiment. ${ }^{13,14}$ However, this repulsive state can be directly reached by $234 \mathrm{~nm}$ excitation $(5.31 \mathrm{eV})$ and may be the origin of the high-velocity components in the total translational energy distribution.

\section{Summary}

In the present study, the photodissociation dynamics of bromobenzene $\left(\mathrm{C}_{6} \mathrm{H}_{5} \mathrm{Br}\right)$ has been investigated at $234 \mathrm{~nm}$ using a photofragment ion-imaging technique coupled with a stateselective REMPI scheme. In $\mathrm{C}_{6} \mathrm{H}_{5} \mathrm{Br}$, the nascent $\mathrm{Br}$ atoms are produced from the primary $\mathrm{C}-\mathrm{Br}$ bond dissociation, which leads to the formation of $\mathrm{C}_{6} \mathrm{H}_{5}(\tilde{X})$ and $\mathrm{Br}\left({ }^{2} \mathrm{P}_{j}, j=1 / 2,3 / 2\right)$. The obtained translational energy distributions were well fitted by a single Boltzmann function and two Gaussian functions. On the basis of the potential energy surfaces obtained from recent multireference CASSCF and CASPT2 calculations, the lowestenergy Gaussian components were assigned to the curve crossing from the initially pumped $B_{2}{ }^{1}\left(\pi, \pi^{*}\right)$ state to the repulsive $B_{1}{ }^{3}\left(n, \sigma^{*}\right)$ state. The highest accessible $B_{1}{ }^{3}\left(n, \sigma^{*}\right)$ state has been considered to be the origin of the highest Gaussian components. The observed recoil anisotropy and width of the Gaussian functions were also consistent with the abovementioned assignment. Finally, it is suggested that the intersystem crossing followed by the excitation from the $\operatorname{singlet}{ }^{1}\left(\pi, \pi^{*}\right)$ state to the ground 
state was responsible for the Boltzmann component. To better understand the effect of substituents on the photodissociation of aryl halide molecules, we are currently investigating the various benzene halides and other molecules that have conjugated $\mathrm{C}=\mathrm{C}$ bonds.

Acknowledgments. This study was supported for two years by Pusan National University Research Grant.

\section{References}

1. Sparks, R. K.; Shobadake, K.; Carlson, L. R.; Lee, Y. T. J. Chem. Phys. 1981, 75, 3838.

2. Kim, T. K.; Lee, K. W.; Lee, K. S.; Lee, E. K.; Jung, K. H. Chem. Phys. Lett. 2007, 446, 31.

3. Kim, T. K.; Park, M. S.; Lee, K. W.; Jung, K. H. J. Chem. Phys. 2001, 115, 10745.

4. Lee, K. S.; Lee, K. W.; Lee, S. K.; Jung, K. H.; Kim, T. K. J. Mol. Spectra. 2008, 249, 43.

5. Eppink, A. T. J. B.; Parker, D. H. J. Chem. Phys. 1999, 110, 832.

6. Lee, K. W.; Jee, Y. J.; Jung, K. H. J. Chem. Phys. 2002, 115, 4490.

7. Lee, K. S.; Paul, D.; Hong, K.; Cho, H. N.; Jung, K. W.; Kim, T. K. Bull. Korean Chem. Soc. 2009, 30, 2962.

8. Zou, P; McGiven, W. S.; North, S. W. Phys. Chem. Chem. Phys. 2000, 2, 3785.

9. Amatatsu, Y.; Yabushita, S.; Morokuma, K. J. Chem. Phys. 1996, 104, 9783.

10. Hua, L.; Shen, H.; Zhang, C.; Cao, Z.; Zhang, B. Chem. Phys. Lett. 2008, 460,50 .

11. Zhang, H.; Zhu, R. S.; Wang, G. J.; Han, K. L.; He, G. Z.; Lou, N. Q. J. Chem. Phys. 1999, 110, 2922.

12. Tang, B.; Zhu, R.; Tang, Y.; Ji, L.; Zhang, B. Chem. Phys. Lett. 2003, 381, 617.

13. Liu, Y. J.; Persson, P.; Lunell, S. J. Phys. Chem. A 2004, 108, 2339.

14. Liu, Y. J.; Persson, P.; Karlsson, H. O.; Lunell, S.; Kadi, M.; Karl- sson, D.; Davidsson, J. J. Chem. Phys. 2004, 120, 6502.

15. Kavita, K.; Das, P. K. J. Chem. Phys. 2002, 117, 2038.

16. Kadi, M.; Davidsson, J.; Tarnovsky, A. N.; Rasmusson, M.; Akesson, E. Chem. Phys. Lett. 2001, 350, 93.

17. Ichimura, T.; Mori, Y.; Shinohara, H.; Nishi, N. Chem. Phys. 1994, $189,117$.

18. Hwang, H. J.; El-sayed, M. A. J. Chem. Phys. 1992, 96, 856.

19. Freedman, A.; Yang, S. C.; Kawasaki, M.; Bersohn, R. J. Chem. Phys. 1980, 72, 1028 .

20. Cheng, P. Y.; Zhong, D.; Zewail, A. H. Chem. Phys. Lett. 1995, 237, 399.

21. Zhong, D.; Zewail, A. H. J. Phys. Chem. A 1998, 102, 4031.

22. Kawasaki, M.; Lee, S. J.; Bersohn, R. J. Chem. Phys. 1980, 72, 1028.

23. Ichimura, T.; Mori, Y.; Shinohara, H.; Nishi, N. J. Chem. Phys. $1997,107,835$.

24. Dzvonik, M.; Yang, S.; Bersohn, R. J. Chem. Phys. 1974, 61, 4408.

25. Kadi, M.; Ivarsson, E.; Davidsson, J. Chem. Phys. Lett. 2004, $384,35$.

26. Kadi, M.; Davidsson, J. Chem. Phys. Lett. 2003, 378, 172.

27. Gu, X. B.; Wang, G. J.; Huang, J. H.; Han, K. L.; He, G. Z.; Lou, N. Q. J. Phys. Chem. A 2001, 105, 354.

28. Kang, W. K.; Kim, Y. S.; Jung, K. H. Chem. Phys. Lett. 1995, 244 , 183.

29. Eppink, A. T. J. B.; Parker, D. H. Rev. Sci. Instrum. 1997, 68, 3477.

30. Park, M. S.; Jung, Y. J.; Lee, S. H.; Kim, D. C.; Jung, K. H. Chem. Phys. Lett. 2000, 322, 429.

31. Hansen, E. W.; Law, P. L. J. Opt. Soc. Am. A 1985, $2,510$.

32. Zare, R. N.; Herschbach, D. R. Proc. IEEE 1963, 51, 173.

33. Park, M. S.; Lee, K. W.; Jung, K. H. J. Chem. Phys. 2001, 114, 10368.

34. Ajitha, D.; Fedorov, D. G.; Finley, J. P.; Hirao, K. J. Chem. Phys. 2002, 117, 7068 .

35. Frietas, J. E.; Hwang, H. J.; El-sayed, M. A. J. Phys. Chem. 1995, 99, 7395.

36. Lee, K. S.; Lee, K. W.; Kim, T. K.; Ryoo, R.; Jung, K. H. J. Chem. Phys. 2005, 122, 034308. 